\title{
openheart Echocardiographic subtypes of heart failure in consecutive hospitalised patients with dyspnoea
}

\author{
Olav Wendelboe Nielsen, ${ }^{\oplus 1}$ Nana Valeur, ${ }^{1}$ Ahmad Sajadieh, ${ }^{1}$ \\ Andreas Fabricius-Bjerre, ${ }^{1}$ Christian Malchau Carlsen, ${ }^{1}$ Lars Kober $^{2}$
}

\begin{abstract}
- Additional material is published online only. To view please visit the journal online (http://dx.doi.org/10.1136/ openhrt-2018-000928).
\end{abstract}

To cite: Nielsen OW, Valeur N, Sajadieh A, et al. Echocardiographic subtypes of heart failure in consecutive hospitalised patients with dyspnoea. Open Heart 2019;6:e000928. doi:10.1136/ openhrt-2018-000928

Received 16 0ctober 2018 Revised 15 April 2019 Accepted 26 April 2019

\section{Check for updates}

(C) Author(s) (or their employer(s)) 2019. Re-use permitted under CC BY-NC. No commercial re-use. See rights and permissions. Published by BMJ.

${ }^{1}$ Department of Cardiology, Copenhagen University Hospital Bispebjerg, Copenhagen NV, Denmark

${ }^{2}$ Department of Cardiology, Rigshospitalet, Copenhagen, Denmark

\section{Correspondence to}

Dr Olav Wendelboe Nielsen; own@dadlnet.dk

\section{ABSTRACT}

Heart failure with preserved ejection fraction (HFpEF) involves half of hospitalised patients with heart failure (HF), but estimates vary due to unclear diagnostic criteria. We performed a prospective observational study of hospitalised patients admitted with dyspnoea. The aim was to apply contemporary guidelines to diagnose $\mathrm{HF}$ due to valvular disease (HFvhd), HF due to reduced ejection fraction (HFrEF), HF due to midrange EF (HFmrEF) and $\mathrm{HFpEF}$ in relation to presumed cardiac or non-cardiac dyspnoea.

Methods We included consecutive hospitalised patients with presumed HF or dyspnoea and excluded patients with acute coronary syndrome, estimated glomerular filtration rate $<30 \mathrm{~mL} / \mathrm{min} / 1.73 \mathrm{~m}^{2}$ or low NT-proBNP (<296 ng/L). Higher age-adjusted NT-proBNP values excluded patients with presumptive non-cardiac dyspnoea. Contemporary criteria for HFpEF and diastolic dysfunction were assessed, and we adjudicated whether acute decompensated HF (ADHF) had been the primary diagnosis.

Results 0 f 707 eligible patients, we included 370 patients of whom 75 had non-cardiac dyspnoea. Of these, 10\% (38/370) had no cardiac dysfunction. Cardiac dysfunction consisted of $18.4 \%$, HFvhd, $30.1 \%$ HFrEF, $10.2 \%$ HFmrEF and $41.3 \% \mathrm{HFpEF}$. HFpEF was twice as common in presumptive non-cardiac dyspnoea versus cardiac dyspnoea $(71 \%$ vs $34 \%, p<0.0001)$. However, adjudicated ADHF was the primary diagnosis in $80 \%$ of $\mathrm{HFrEF}, 62 \%$ of HFmrEF and just $28 \%$ of HFpEF.

Conclusion HF according to contemporary criteria applied to $90 \%$ of patients admitted with dyspnoea and elevated NT-proBNP irrespective of the presumptive cause of dyspnoea, of whom $10 \%$ had HFmrEF and $41 \%$ HFpEF. However, significant non-cardiac diagnoses related to 9 out of 10 with HFpEF with pulmonary disease as the predominant adjudicated problem.

\section{INTRODUCTION}

Heart failure with preserved ejection fraction (HFpEF) involves $50 \%$ of hospitalised patients with heart failure (HF), ${ }^{1}$ but evaluation of the scale of the problem varies due to unclear diagnostic criteria, ${ }^{2}$ comorbidity and various types of hospitals. ${ }^{1}$ Previous registry studies of HF epidemiology were not based on comprehensive echocardiograms, and

\section{Key questions}

What is already known about this subject?

- Heart failure with preserved ejection fraction (HFpEF) involves $50 \%$ of hospitalised patients with heart failure (HF).

- Dyspnoea is the cardinal symptom of HF, but dyspnoea is frequently caused by non-cardiac comorbidity.

What does this study add?

- The majority of previous studies did not examine consecutive patients with dyspnoea and did not base their HF diagnosis on natriuretic peptides and a comprehensive echocardiogram with evaluation of diastolic function.

- In our prospective observational study, we asked, 'what is the diagnostic outcome of applying European Society of Cardiology (ESC) criteria including natriuretic peptide and a comprehensive echocardiogram to consecutive patients admitted with dyspnea?'.

- The echocardiogram showed cardiac dysfunction, and therefore $\mathrm{HF}$, in $90 \%$ of patients admitted with dyspnoea and elevated NT-proBNP, where $41 \%$ had HFpEF, and $10 \%$ HF with EF $40 \%-49 \%$. However, pulmonary disease was the predominant adjudicated clinical diagnosis in patients who fulfilled contemporary echocardiographic criteria for HFpEF.

How might this impact on clinical practice?

- This study supports that HF is a frequent complication in pulmonary disease, and we show the outcome of using the 2016 ESC guideline strategy to identify $\mathrm{HF}$ in consecutive patients admitted with dyspnoea.

- Although HFmrEF and HFpEF subtypes accounts for half of all HF, 9 out of 10 have significant non-cardiac disease as the predominant adjudicated problem, which calls for a multidisciplinary management plan and more research addressing this particular problem.

they rarely describe the underlying subtype of HF. Knowing the subtype of HF is essential for selecting evidence-based treatment, but there seems to be a mismatch between 
patients entering randomised clinical trials and patients seen in clinical practice. ${ }^{3}$

Recent guidelines authorise the use of natriuretic peptide to rule out $\mathrm{HF}^{4}$; they acknowledge left ventricular (LV) hypertrophy and enlarged left atrium (LA) as a reason for HFpEF and give clear criteria for diastolic dysfunction. ${ }^{45}$ The doorway to finding patients with HF is to examine patients with dyspnoea, and therefore, we asked, "what is the diagnostic outcome of applying novel guideline criteria including a comprehensive echocardiogram to consecutive patients admitted with dyspnea?'.

We used a prospective observational study to describe the subtype of cardiac dysfunction, if any, among all comers admitted with dyspnoea. Although data were collected in $2010,{ }^{6}$ the recent 2016 guidelines were used to diagnose $\mathrm{HFpEF}$ and 'HFmrEF' ${ }^{4}$ (midrange LV EF from $40 \%$ to $49 \%$ ). The aim was to describe the frequency of subtypes of cardiac dysfunction in patients hospitalised with dyspnoea and elevated NT-proBNP, in relation to HFpEF, HFmrEF and HF due to reduced EF (HFrEF) and to examine the impact of non-cardiac comorbidity.

\section{METHODS}

\section{Study design and population}

The Copenhagen Heart Failure with Preserved Ejection Fraction study was designed as a prospective observational study to evaluate all patients $\geq 40$ years of age admitted with acute dyspnoea to the acute medical unit, general medicine ward and department of cardiology at Bispebjerg University Hospital, a non-tertiary hospital serving about 250000 people in 2010. Patients from the accidents and emergency department were examined only if they were subsequently hospitalised. Screening was performed at 180 predefined randomly selected study days between 16 November 2009 and 31 July 2011, covering all days of the week.

The Danish regional ethical committee waived requirement for informed consent because NT-proBNP measurement and echocardiography were considered appropriate examinations and the study was classified as a prospective registry.

Patients were identified by a research fellow in cardiology (CMC) who screened all medical records within the first 24 hours after non-elective admission. The research fellow verified data from the clinically working physicians and collected supplementary baseline data including previous and presumptive diagnoses (see figure 1).

\section{Inclusion criteria and presumptive cause of dyspnoea}

Patients were eligible if dyspnoea (any sensation of shortness of breath, resting dyspnoea, orthopnoea or paroxysmal nocturnal dyspnoea) or suspected HF was the dominant or codominant reason for admission. The initial presumptive causes of dyspnoea, as made by the staff physicians within 24 hours, were systematically reviewed by the research fellow and categorised into: (1)

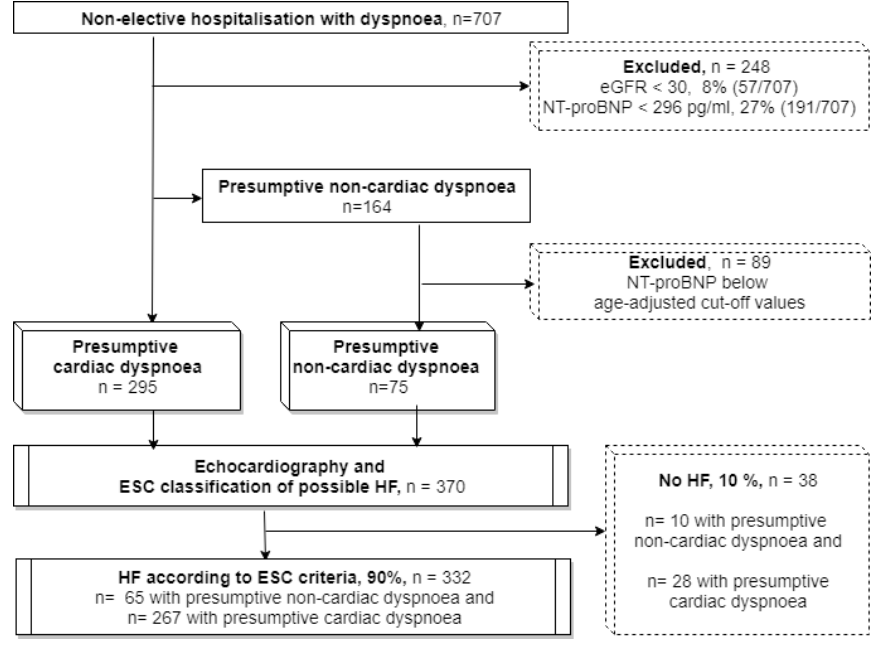

Figure 1 Consort diagram of patients. eGFR, estimated glomerular filtration rate; $\mathrm{HF}$, heart failure.

non-cardiac dyspnoea or (2) presumptive cardiac dyspnoea based on the following criteria.

\section{Non-cardiac dyspnoea}

- Patients presenting with obvious non-cardiac conditions: known irreversible intractable chest malignancy, previous admissions with documented severe chronic obstructive pulmonary disease (COPD) and forced expiratory volume $<50 \%$ of expected value in an outpatient setting, previous COPD admission with need of home oxygen prior to admission, acute pneumonia documented on X-ray, or acute pulmonary embolism, severe anaemia (haemoglobin $<5$ $\mathrm{mmol} / \mathrm{L}$ ) or severe obesity (body mass index $>40$ ).

\section{Presumptive cardiac dyspnoea}

- Remaining patients were classified as presumptive cardiac dyspnoea, also including dyspnoea of unknown aetiology (figure 1).

\section{Exclusion criteria}

Patients were excluded if they had chronic kidney disease stage 4 and 5 with an estimated glomerular filtration rate (eGFR) $<30 \mathrm{~mL} / \mathrm{min} / 1.73 \mathrm{~m}^{2}$ using the Modification of Diet in Renal Disease formula, or if they had predominantly chest pain with acute coronary syndrome and scheduled for an acute coronary angiogram. Patients with presumptive non-cardiac dyspnoea were excluded if NT-proBNP was under the below mentioned age-adjusted rule-in values.

\section{NT-proBNP analysis}

NT-proBNP was analysed at time of admission using a commercially available immunoassay (Elecsys NT-proBNP, Roche Diagnostics, pmol/L) on the Cobas e 411 platform. Our laboratory reports an inter-run coefficient of variation $<2.0 \%$. The rule out threshold was NT-proBNP concentration $<35 \mathrm{pmol} / \mathrm{L}$, equal to $296 \mathrm{ng} / \mathrm{L}$ (to convert ng/L to pmol/L, multiply by 0.118$).{ }^{7}$ Patients with presumptive non-cardiac dyspnoea were excluded if 
NT-proBNP $<50 \mathrm{pmol} / \mathrm{L}$ (423 ng/L) for age 40-49 years; $<100 \mathrm{pmol} / \mathrm{L}$ (846 ng/L) for age 50-74 years; and <200 $\mathrm{pmol} / \mathrm{L}$ (1691 ng/L) for age 75 years or more. These values are slightly lower than the age adjusted rule-in values of $450 \mathrm{ng} / \mathrm{L}, 900 \mathrm{ng} / \mathrm{L}$ and $1800 \mathrm{ng} / \mathrm{L}$ that were previously recommended for the respective age groups. ${ }^{78}$

\section{Echocardiogram}

A comprehensive echocardiogram was performed by the cardiology fellow in all included patients (figure 1) within 48 hours of admission, unless an echocardiogram within the last 3 months existed and documented an left ventricular ejection fraction (LVEF) $<40 \%$ or severe valvular heart disease (VHD). The echocardiogram included systematic evaluation of cardiac structure and function, ${ }^{9}$ and all patients with LVEF of $40 \%$ or above were examined for diastolic dysfunction. ${ }^{10}{ }^{11}$ Measurements equalled the median over 3-5 cardiac cycles when patients had sinus rhythm and median over 5-10 cycles for patients in atrial fibrillation (AF).

LVEF and severe valve disease were reported to the clinical staff promptly, but remaining parameters were analysed later on stored images (Xcelera system by Philips). Validation of the individual echocardiographic parameters was performed by a second reviewer (OWN and/ or LK). LA maximum volume was calculated in fourchamber and two-chamber view using the area length formula. ${ }^{12}$ Key structural alterations were defined as: LA maximum volume index $>34 \mathrm{~mL} / \mathrm{m}^{2}$ and $\mathrm{LV}$ hypertrophy, defined as LV mass index $\geq 115 \mathrm{~g} / \mathrm{m}^{2}$ for males and $\geq 95 \mathrm{~g} / \mathrm{m}^{2}$ for females. ${ }^{4}$ For the present analyses, we defined 'definite diastolic dysfunction' according to a recent consensus paper ${ }^{5}$ as the presence of 3 or 4 of the following four parameters: velocity of septal $\mathrm{e}^{\prime}<7 \mathrm{~cm} / \mathrm{s}$ or lateral $\mathrm{e}^{\prime}<10 \mathrm{~cm} / \mathrm{s}$; average $\mathrm{E} / \mathrm{e}^{\prime}$ ratio $>14$; LA maximum volume index $>34 \mathrm{~mL} / \mathrm{m}^{2}$; peak TR velocity $>2.8 \mathrm{~m} / \mathrm{s}$. $\mathrm{e}^{\prime}$ was calculated as the mean from anterior, posterior, septal and lateral walls.

\section{ESC classification of HF subtypes}

Evidence for abnormal cardiac function or structure were classified according to 2016 ESC criteria, ${ }^{4}$ where severe VHD was classified first to avoid interference of VHD with subsequent grouping. Hence, cardiac dysfunction was classified in the ranked order:

1. First, in case of severe VHD, patients were classified as 'HFvhd'.

2. The remaining with $\mathrm{LVEF}<40 \%$ were denoted $\mathrm{HF}$ with reduced EF, that is, 'HFrEF'.

3. The remaining with LVEF from $40 \%$ to $49 \%$ were classified as 'HFmrEF'.

4. The remaining with LVEF $\geq 50 \%$ who had 'definite diastolic dysfunction', LA enlargement or LV hypertrophy were denoted as 'HFpEF'.

5. The rest with LVEF $\geq 50 \%$ and 'indeterminate or no definite LV diastolic dysfunction' were denoted as 'not HF'.

\section{Clinical scores of HF signs and comorbidity}

The research fellow documented all subjective and objective signs and symptoms needed for the Framingham and Boston heart failure score. ${ }^{13} 14$ The Boston HF score adds signs and symptoms into a score from 0 to 12 where $0-4$ denote 'unlikely HF', 5-7 denote 'possible HF' and 8-12 denote 'definite HF'. The Charlson Comorbidity Index was calculated as the total of the patient's comorbid conditions, which had been weighted without giving weight to age. ${ }^{1516}$

\section{Adjudicated primary diagnosis}

Acute decompensated HF (ADHF) was adjudicated as the primary diagnosis if ADHF had been the most significant problem during admission based on review of medical records, staff diagnoses and echocardiography. The adjudicated diagnosis required consensus among the clinical working cardiologists and the research fellow in cardiology. In case of inconsistency or doubt, the final diagnosis was further adjudicated by additional two cardiologists (OWN and LK). To minimise the ambiguity of clinical judgement, the definition of ADHF relied on documentation of central or peripheral fluid retention as the most significant clinical problem, with an adequate response to diuretic therapy, accompanied by abnormal function or structure in the reviewed echocardiogram. Reversible reasons for acute decompensation such as arrhythmias or abnormal loading conditions were also considered valid reasons for ADHF.

\section{Statistics}

Values are expressed as means and SD, medians and quartiles or counts and percentages as appropriate in relation to normality.

Participants with missing values were minimised by adhering to the inclusion and exclusion criteria. No imputation was made for participants with missing values, but data validity was ensured by reporting variables for subgroups with a high rate of non-missing values (see online supplementary table for missing values). Sensitivity analyses were inherently performed for patients with and without cardiac dyspnoea and by comparing diastolic function to patients with 'No HF'. NT-proBNP was transformed with the natural logarithm before comparing mean values in trend analyses. Univariate analyses of variables between groups were performed with the Kruskall-Wallis test and non-parametric test for trend examined trends between groups. $\mathrm{P}<0.05$ was taken to indicate significance and all statistical analyses were performed using Stata V.13 statistical software.

\section{RESULTS}

\section{Population}

Seven hundred and seven patients with dyspnoea were eligible during 180 days of screening, after excluding 57 patients due to chronic kidney disease and 191 with low NT-proBNP values (figure 1). The 191 patients excluded 
Table 1 Characteristics of patients according to presumptive working diagnosis

\begin{tabular}{|c|c|c|c|c|}
\hline & $\begin{array}{l}\text { Presumptive cardiac } \\
\text { dyspnoea }\end{array}$ & $\begin{array}{l}\text { Presumptive non- } \\
\text { cardiac dyspnoea }\end{array}$ & $P$ value \\
\hline \multicolumn{2}{|l|}{$\mathrm{N}$} & 295 & 75 & \\
\hline \multicolumn{2}{|l|}{ Age, mean (SD) } & $77.0(11.9)$ & $72.9(10.9)$ & 0.007 \\
\hline \multicolumn{2}{|l|}{ Female gender } & $145(49.2 \%)$ & $43(57.3 \%)$ & 0.21 \\
\hline \multicolumn{2}{|l|}{ Previous hosp for HF } & $98(33.2 \%)$ & $7(9.3 \%)$ & $<0.001$ \\
\hline \multicolumn{2}{|l|}{ Known valve disease } & $36(12.2 \%)$ & $2(2.7 \%)$ & 0.015 \\
\hline \multicolumn{2}{|l|}{ Known HFrEF } & $56(19.0 \%)$ & $0(0.0 \%)$ & $<0.001$ \\
\hline \multicolumn{2}{|l|}{ IHD } & $76(25.8 \%)$ & $12(16.0 \%)$ & 0.076 \\
\hline \multicolumn{2}{|l|}{ Diabetes } & $61(20.7 \%)$ & $16(21.3 \%)$ & 0.90 \\
\hline \multicolumn{2}{|l|}{ COPD } & $91(30.8 \%)$ & $51(68.0 \%)$ & $<0.001$ \\
\hline \multicolumn{2}{|c|}{ Atrial fibrillation, history or new } & $150(50.8 \%)$ & $27(36.0 \%)$ & 0.022 \\
\hline \multicolumn{2}{|c|}{ Hypertension, history or $\geq 140 / 90 \mathrm{~mm} \mathrm{Hg}$} & $216(73.2 \%)$ & $47(62.7 \%)$ & 0.072 \\
\hline \multicolumn{2}{|c|}{ Anaemia $(\mathrm{HgB}<8.1 \mathrm{M}$ or $<7.4 \mathrm{~F})$} & $116(39.3 \%)$ & $39(52.0 \%)$ & 0.047 \\
\hline Chronic kidney disease & $\geq 90$ & $46(15.7 \%)$ & $13(17.3 \%)$ & 0.86 \\
\hline \multirow[t]{2}{*}{ Groups from eGFR } & $60-89$ & $127(43.3 \%)$ & $30(40.0 \%)$ & \\
\hline & $30-59$ & $120(41.0 \%)$ & $32(42.7 \%)$ & \\
\hline \multicolumn{2}{|l|}{ NT-proBNP, median (IQR), ng/L } & $3102(1322,8729)$ & $2712(1686,9034)$ & 0.74 \\
\hline \multicolumn{2}{|c|}{ Charlson Comorbidity Index, mean (SD) } & $2.5(1.9)$ & $3.1(2.3)$ & 0.023 \\
\hline \multicolumn{5}{|c|}{ Signs and symptoms of HF on examination } \\
\hline \multirow[t]{3}{*}{ Boston score } & 0-4 point & $30(10.2 \%)$ & $3(4.0 \%)$ & 0.005 \\
\hline & 5-7 point & $83(28.1 \%)$ & $35(46.7 \%)$ & \\
\hline & 8-12 point & $182(61.7 \%)$ & 37 (49.3\%) & \\
\hline \multirow[t]{2}{*}{ Framingham HF } & Negative & 100 (33.9\%) & $42(56.0 \%)$ & $<0.001$ \\
\hline & Positive & $195(66.1 \%)$ & $33(44.0 \%)$ & \\
\hline
\end{tabular}

COPD, chronic obstructive pulmonary disease;HF, heart failure; HFrEF, heart failure due to reduced EF; IHD, ischaemic heart disease; eGFR, estimated glomerular filtration rate.

because of low NT-proBNP had a mean age of 62.7 (SD 12.6) years, eGFR of 80.9 (SD 14.5), NT-proBNP of 129 (SD 68) ng/L, 57\% had COPD/asthma and 2.7\% AF. Of 164 patients with presumptive non-cardiac dyspnoea, we excluded 89 who had NT-proBNP below the age-adjusted rule-in values. Hence, a total of 370 patients were included of whom 295 patients had presumptive cardiac dyspnoea and 75 had presumptive non-cardiac dyspnoea (figure 1). Significant signs or symptoms of HF related to more than $90 \%$ of patients, as indicated by a Boston score above 4 points. (table 1 )

\section{HF subtypes in examined patients}

No cardiac dysfunction was found in $10 \%$ of included patients (figures land and 2) (38/370, 95\% CI $7 \%$ to $13 \%)$, with similar rates for presumptive non-cardiac and cardiac dyspnoea ( $13.5 \%$ vs 9\%, ns.). Among 332 patients with cardiac dysfunction, $10.2 \%$ had HFmrEF $(34 / 332$, $95 \%$ CI $7 \%$ to $14 \%)$ and $41 \%$ HFpEF $(137 / 332,95 \%$ CI $35 \%$ to $47 \%$ ). HFpEF was twice as common in patients with presumptive non-cardiac dyspnoea as compared with presumptive cardiac dyspnoea $(70.8 \%$ vs $34.1 \%$, $\mathrm{p}<0.0001$, figure 3 ). Of the 62 patients with severe valve disease, $42 \%$ (26/62, 95\% CI 20\% to 54\%) also had LVEF $<40 \%$.

\section{Patients characteristics in relation to HF subtype}

Moving from HFrEF over HFmrEF to HFpEF there was a significant trend for higher age, more females, lower diastolic BP, higher pulse pressure and lower NT-proBNP (table 2). HFmrEF was comparable with HFrEF in most aspects, apart from less comorbidity and a higher age in HFmrEF patients. HFmrEF was associated with significantly more of $\mathrm{AF}$ and ischaemic heart disease as compared with HFpEF.

Acute decompensated HF was adjudicated as the primary clinical diagnosis in $80 \%$ of $\mathrm{HFrEF}, 62 \%$ of HFmrEF and $27.7 \%$ of HFpEF (figure 4 and table 3). Similarly, pulmonary disease was the most frequent adjudicated primary clinical diagnosis in patients classified as HFpEF (table 3).

HFpEF without a non-cardiac adjudicated primary diagnosis related to just $11 \%(38 / 332)$ of all patients fulfilling the ESC criteria for HF ( $\mathrm{n}=38$ with ADHF in table 3$)$. 


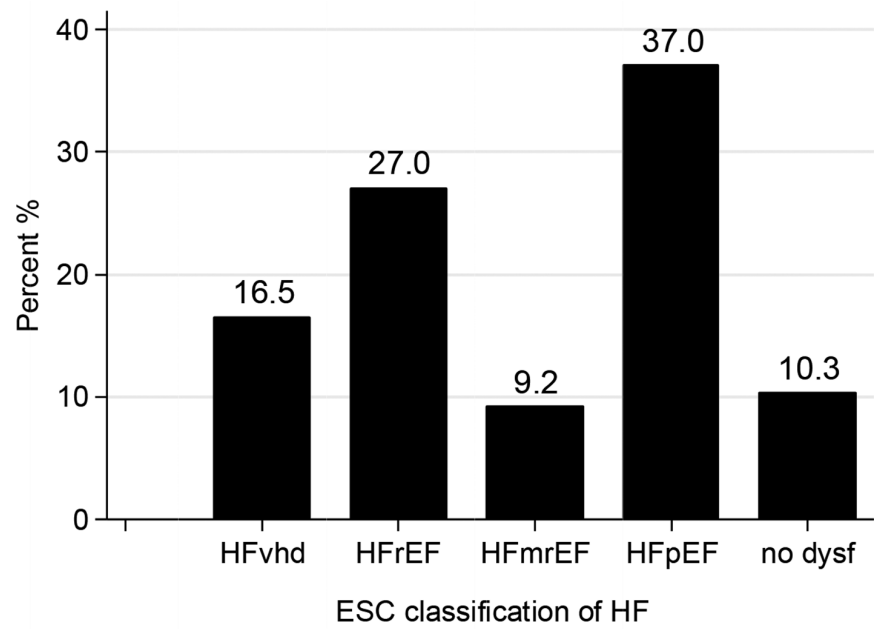

Figure 2 Percentage distribution of ESC HF subtypes and no cardiac dysfunction (no dysf, $\mathrm{n}=38$ ) among all 370 included patients, where HFvhd is HF due to valvular heart disease $(n=61)$, HFrEF is HF with reduced ejection fraction $(n=100), H F p r E F$ is HF with mid range ejection fraction $(n=34)$ and HFpEF is HF with preserved ejection fraction $(n=137)$. $E F$, ejection fraction; HF, heart failure; HFmrEF, HF due to midrange EF; HFpEF, HF with preserved EF; HFrEF, HF due to reduced EF.

\section{Diastolic dysfunction in patients with LVEF of $\mathbf{4 0} \%$ or more}

'Definite' diastolic dysfunction was observed in $62 \%$ of HFmrEF and $60 \%$ of HFpEF based on diastolic function parameters (table 4), while 'normal' diastolic function comprised less than $10 \%$ in HFmrEF and HFpEF. More than $95 \%$ of HFmrEF and HFpEF patients had enlarged LA. Indeterminate diastolic dysfunction was observed

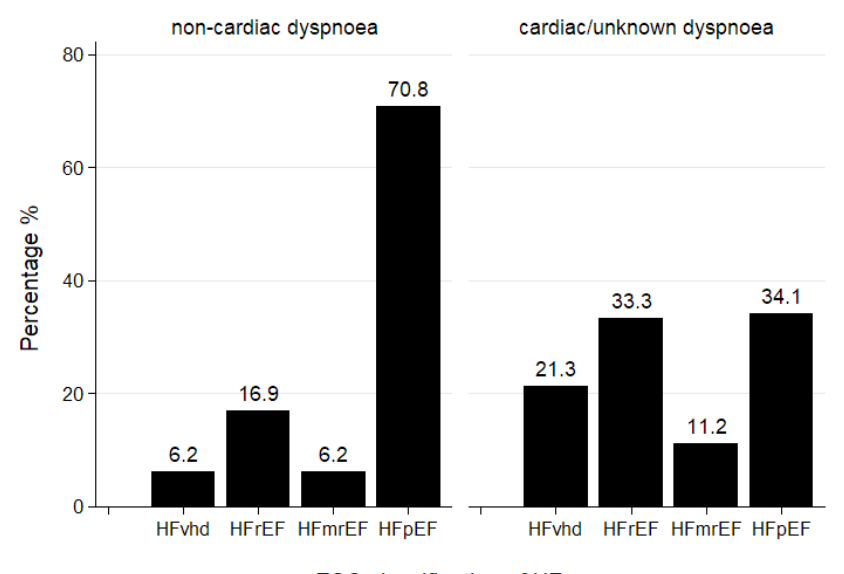

Figure 3 Percentage distribution of ESC types of cardiac dysfunction among 65 patients with presumptive non-cardiac dyspnoea: HFvhd $(n=4) ; \operatorname{HFrEF}(n=11), \operatorname{HFmrEF}(n=4)$ and HFpEF ( $n=46)$, and 267 HF patients with presumptive cardiac dyspnoea: HFvhd ( $n=57)$; HFrEF $(n=89), \operatorname{HFmrEF}(n=30)$ and HFpEF ( $n=91)$. EF, ejection fraction; HF, heart failure; HFmrEF, HF due to midrange EF; HFpEF, HF with preserved ejection fraction; HFrEF, HF due to reduced EF; HFvhd, HF due to valvular disease. in about one-third of all subtypes including the 'no HF' group (table 4 ).

\section{DISCUSSION}

Cardiac dysfunction according to contemporary ESC criteria for HF was demonstrated in $90 \%$ of consecutive hospitalised patients with dyspnoea and elevated NT-proBNP, where $41 \%$ could be ascribed to HFpEF and $10 \%$ to HFmrEF. Presumed non-cardiac dyspnoea and elevated NT-proBNP was associated with a $71 \%$ prevalence of HFpEF, and the diagnosis primarily grounded on structural rather than functional abnormalities since $40 \%$ of HFpEF patients lacked 'definite diastolic dysfunction'. HFpEF presenting as ADHF accounts for merely $11 \%$, not $41 \%$, since pulmonary disease was the predominant adjudicated problem in patients with HFpEF.

\section{HF criteria in clinical studies}

Our study differs from other studies by examining consecutive patients with undifferentiated dyspnoea, instead of just patients with presumptive cardiac dyspnoea. By use of the contemporary 2016 ESC criteria for HF and diastolic dysfunction, merely $10 \%$ did not have one of the ESC HF subtypes, which is unprecedented information.

The ESC criteria for cardiac dysfunction are objective and externally valid. ${ }^{4}$ However, it may be questioned whether LA enlargement and/or LV hypertrophy alone may account for hospitalised HFpEF, because both findings are highly prevalent in elderly patients with hypertension and/or AF. In a recent community-based study, $49 \%$ of patients had one or two abnormal measures of diastolic dysfunction. ${ }^{17}$ Although LA enlargement and LV hypertrophy do not cause HF per se, they predispose to the symptoms and signs of HF by reducing the patients ability to compensate when the cardiovascular system become challenged. ${ }^{18}$

A causal relationship between dyspnoea and HFpEF is more convincing if three or four out of four diastolic dysfunction criteria are abnormal. ${ }^{5}$ However, diastolic dysfunction parameters are dynamic, and the $\mathrm{E} / \mathrm{e}^{\prime}$ and tricuspid regurgitant velocity vary in relation to $\mathrm{LV}$ filling pressure, so timing of echocardiography becomes important. In this study, echocardiography was made within 48 hours of admission, and the Doppler signs of diastolic dysfunction probably diminished in some patients after appropriate treatment.

\section{ESC subtypes of HF}

HFmrEF occurred in $10 \%$, which is lower than previous estimates of $10 \%-20 \%,{ }^{19}$ probably because we classified severe valve disease before all the other subtypes. HFmrEF patients had a higher burden than HFpEF with respect to $\mathrm{AF}$, ischaemic heart disease and $\mathrm{ADHF}$ as the adjudicated primary clinical diagnosis. Just $5.9 \%$ of HFmrEF patients had a normal diastolic function, indicating that HFmrEF patients have a significant cardiac dysfunction.

Although one out of two patients had a LVEF above $40 \%$, at most 1 in 10 could be considered for a clinical 
Table 2 Characteristics of HFrEF, HFmrEF and HFpEF

\begin{tabular}{|c|c|c|c|c|c|}
\hline \multirow[b]{2}{*}{ Characteristic } & & \multirow{2}{*}{$\begin{array}{l}\text { HFrEF } \\
\mathrm{N}=100\end{array}$} & \multirow{2}{*}{$\begin{array}{l}\text { HFmrEF } \\
\mathrm{N}=34\end{array}$} & \multirow{2}{*}{$\begin{array}{l}\text { HFpEF } \\
\mathrm{N}=137\end{array}$} & \multirow{2}{*}{$\begin{array}{l}\mathrm{P} \text { value } \\
\text { trend }\end{array}$} \\
\hline & & & & & \\
\hline Age, mean (SD) & Mean (SD) & $73.2(11.6)$ & $77.2(12.0)$ & $77.1(11.3)^{\star}$ & 0.021 \\
\hline Male, n (\%) & Mean (SD) & $71(71.0 \%)$ & 19 (55.9\%)† & $43(31.4 \%)^{\star}$ & $<0.001$ \\
\hline Body mass index, mean (SD) & Mean (SD) & $26.3(4.9)$ & $28.8(7.8)$ & $26.7(6.2)$ & $\begin{array}{l}0.923 \\
0\end{array}$ \\
\hline Heart rate per min & Mean (SD) & $93.9(26.8)$ & $92.3(26.8)$ & $92.8(22.2)$ & 0.896 \\
\hline BP systolic, mm Hg & Mean (SD) & $140.9(31.2)$ & $143.9(28.0)$ & $143.5(29.3)$ & 0.326 \\
\hline BP diastolic, $\mathrm{mm} \mathrm{Hg}$ & Mean (SD) & $83.1(22.0)$ & $80.6(20.6)$ & $75.1(16.5)^{\star}$ & 0.008 \\
\hline Pulse pressure, $\mathrm{mm} \mathrm{Hg}$ & Mean (SD) & $57.8(22)$ & $63.3(21.2)$ & $68.1(21.4)^{\star}$ & $<0.001$ \\
\hline Respiratory rate, per min & Mean (SD) & $23.4(7.3)$ & $21.8(5.4)$ & $23.4(6.8)$ & 0.656 \\
\hline NT-proBNP, ng/L & Mean (SD) & 8700 (8701) & 6151 (7598)† & $2987(3392)^{\star}$ & $<0.001$ \\
\hline NT-proBNP in intervals & $0-422$ & $1(1.0 \%)$ & $0(0.0 \%)$ & $9(6.6 \%)^{*}$ & $<0.001$ \\
\hline \multirow[t]{3}{*}{ Groups ng/L } & $423-845$ & $4(4.0 \%)$ & $4(11.8 \%)$ & $11(8.0 \%)$ & \\
\hline & $846-1690$ & $10(10.0 \%)$ & $8(23.5 \%)$ & $34(24.8 \%)$ & \\
\hline & $1691+$ & $85(85.0 \%)$ & $22(64.7 \%)$ & $83(60.6 \%)$ & \\
\hline \multicolumn{6}{|l|}{ Clinical signs of heart failure } \\
\hline Dyspnoea at rest & Number (\%) & $42(42.0)$ & $12(35.3)$ & $74(54.0)$ & 0.057 \\
\hline Functional dyspnoea & Number (\%) & $86(86.0)$ & $30(88.2)$ & $126(92.0)$ & 0.140 \\
\hline Dyspnoea when walking stairs & Number (\%) & $99(99.0)$ & $33(97.1)$ & $133(97.1)$ & 0.331 \\
\hline Rales on auscultation & Number (\%) & $51(51.0)$ & $14(41.2)$ & $62(45.3)$ & 0.405 \\
\hline Rhonchi on auscultation & Number (\%) & $23(23.0)$ & $7(20.6) \dagger$ & $60(43.8)^{*}$ & 0.001 \\
\hline Congestion on chest X-ray & Number (\%) & $41(41.0) \ddagger$ & $5(14.7)$ & $28(20.4)^{\star}$ & 0.001 \\
\hline \multicolumn{6}{|l|}{ Echocardiography } \\
\hline LVEF \% & Mean (SD) & $27.4(7.4) \ddagger$ & $44.0(2.8) \dagger$ & $58.5(5.7)^{\star}$ & $<0.001$ \\
\hline LV mass index, & Mean (SD) & 117.7 (31.3)‡ & $97.4(20.6) \dagger$ & $87.8(23.0)^{*}$ & $<0.001$ \\
\hline LA volume index, $\mathrm{mL} / \mathrm{m}^{2}$ & Mean (SD) & $59.6(16.0)$ & $58.7(20.4) \dagger$ & $51.8(15.9)^{\star}$ & 0.001 \\
\hline IVSd (cm) & Mean (SD) & $1.1(0.2)$ & $1.1(0.2) \dagger$ & $1.0(0.2)$ & 0.206 \\
\hline LVDd (cm) & Mean (SD) & $5.5(0.7) \ddagger$ & $5.0(0.7) \dagger$ & $4.6(0.6)^{\star}$ & $<0.001$ \\
\hline PWTd (cm) & Mean (SD) & $1.0(0.2)$ & $0.9(0.2)$ & $0.9(0.2)^{\star}$ & 0.003 \\
\hline
\end{tabular}

${ }^{*} \mathrm{P}<0.05$ for individual comparison: HFrEF versus HFpEF.

$\dagger \mathrm{P}<0.05$ for individual comparison: HFmrEF versus HFpEF.

$\ddagger \mathrm{P}<0.05$ for individual comparison: HFrEF versus HFmrEF.

$\mathrm{BP}$, blood pressure; EF, ejection fraction; HF, heart failure; HFmrEF, HF due to midrange EF; HFpEF, HF with preserved EF; HFrEF, HF due to reduced EF; IVSd, interventricular septum in diastole; LA, left atrium; LV, left ventricular; LVDd, left ventricular diameter in diastole; PWTd, posterior wall thickness in diastole.

trial evaluating new therapy for HFpEF, calculated as an overall $41.3 \%$ prevalence of HFpEF (figure 2) of whom $27 \%$ were adjudicated to have ADHF (see figure 4 ).

\section{Use of natriuretic peptides to diagnose $\mathrm{HF}$}

Guidelines recommend NT-proBNP screening in patients presumed to have HF, where a value below 300 $\mathrm{ng} / \mathrm{L}$ rules out HF. However, guidelines are indecisive regarding routine use of NT-proBNP testing in patients with presumptive non-cardiac dyspnoea and recent clinical trials of acute HF included patients based on much higher NT-proBNP values, above $2000 \mathrm{pg} / \mathrm{mL} .^{20} 21$

Our results support that an echocardiogram including evaluation of diastolic function is indicated if NT-proBNP is elevated above the here applied threshold values. A recent study of 80+ year old patients from Singapore and New Zealand showed that similar rule-in values had a sensitivity of $89 \%$ and negative predictive value of $94 \%{ }^{22}$

\section{Problems with diagnosing HF}

The high frequency of comorbidities in consecutive patients with dyspnoea precludes the idea of assigning an 'exclusive' HF diagnosis as the undisputed cause of dyspnoea, and there is an unmet need for guidelines and clinical trials of $\mathrm{HF}$ to address this problem. It is well known that comorbidity begets HF, and comorbidity is much more than an innocent bystander to HF. The mechanisms for pulmonary disease to interact with 


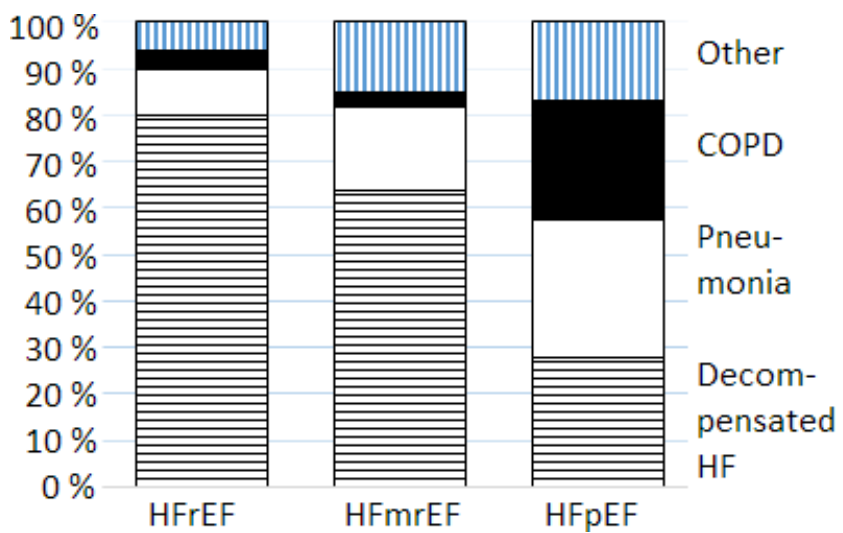

Figure 4 The adjudicated primary diagnosis (HF, pneumonia, COPD or other) that dominated during admission according to ESC HF type: HFrEF ( $n=100)$, HFmrEF $(n=34)$ and HFpEF $(n=137)$. EF, ejection fraction; HF, heart failure; HFmrEF, HF due to midrange EF; HFpEF, HF with preserved EF; HFrEF, HF due to reduced EF.

HFpEF could be through a decreased cardiorespiratory reserve $^{18}$ secondary to systemic inflammation, endothelial dysfunction, increasing load on the peripheral as well as the pulmonic vasculature which lead to higher LV filling pressure, abnormal diastolic function parameters ${ }^{23}$ and pulmonary hypertension. However, there is also a risk that the contemporary diagnostic criteria will 'overdiagnose' HFpEF in patients with preexisting asymptomatic left atrial enlargement ${ }^{24}$ or LV hypertrophy.

\section{Strengths and limitations}

The main advantage of the present study is that the HFpEF diagnosis was evaluated in a large population based on a comprehensive echocardiogram instead of the more widely used incomplete criterion 'lack of an echocardiogram showing a low EF'. Unlike most other studies, we examined consecutive patients and did a systematic prospective work-up in every patient with dyspnoea including a comprehensive echocardiogram and a careful validation in each patient in relation to competing comorbidities. Large registry studies of hospitalised patients with HF do not provide this type of information.

Clinical research in the emergency setting is challenging with a lot of pitfalls, but it is the only way to characterise acute real-world patients presenting with a plethora of presumptive diagnoses. We could not entirely avoid selection bias and excluded stage 4 and 5 kidney disease, because severe kidney disease is known to increase NT-proBNP and induce congestion, and this entity should be subject for a separate investigation. ${ }^{25}$ Our data also do not reflect patients presenting with acute coronary syndrome, critically acute patients who died, were transferred or trivial cases with mild symptoms that were discharged immediately from the emergency room.

Generalisability of our results may not apply to other healthcare systems who have a different level of threshold

\begin{tabular}{|c|c|c|c|c|c|}
\hline \multirow[b]{2}{*}{ Supplementary characteristics } & & HFrEF & HFmrEF & HFpEF & $P$ value \\
\hline & & $\mathrm{N}=100$ & $\mathrm{~N}=34$ & $\mathrm{~N}=137$ & trend \\
\hline \multicolumn{6}{|l|}{ Adjudicated primary diagnosis } \\
\hline Decompensated HF & & $80(80.0 \%)$ & $21(61.8 \%)^{\star}$ & $38(27.7 \%) \dagger$ & $<0.001$ \\
\hline Pneumonia & & $10(10.0 \%)$ & $6(17.6 \%)$ & $41(29.9 \%)$ & \\
\hline COPD & & $4(4.0 \%)$ & $2(5.9 \%)$ & $35(25.5 \%)$ & \\
\hline Other & & $6(6.0 \%)$ & $5(14.7 \%)$ & $23(16.8 \%)$ & \\
\hline NT-proBNP in intervals & $0-422$ & $1(1.0 \%)$ & $0(0.0 \%)$ & $9(6.6 \%) \dagger$ & $<0.001$ \\
\hline \multirow[t]{3}{*}{ groups ng/L } & $423-845$ & $4(4.0 \%)$ & $4(11.8 \%)$ & $11(8.0 \%)$ & \\
\hline & $846-1690$ & $10(10.0 \%)$ & $8(23.5 \%)$ & $34(24.8 \%)$ & \\
\hline & $1691+$ & $85(85.0 \%)$ & $22(64.7 \%)$ & $83(60.6 \%)$ & \\
\hline \multicolumn{6}{|l|}{ Chronic kidney disease } \\
\hline Stage 1 with eGFR & $80+$ & $14(14.1 \%)$ & $4(11.8 \%)$ & $23(16.8 \%)$ & 0.423 \\
\hline Stage 2 with eGFR & $60-79$ & $38(38.4 \%)$ & $18(52.9 \%)$ & $56(40.9 \%)$ & \\
\hline Stage 3 with eGFR & $30-59$ & $47(47.5 \%)$ & $12(35.3 \%)$ & $58(42.3 \%)$ & \\
\hline \multicolumn{6}{|l|}{ Echocardiography } \\
\hline IVSd (cm) & Mean (SD) & $1.1(0.2)$ & $1.1(0.2)^{\star}$ & $1.0(0.2)$ & 0.206 \\
\hline PWTd (cm) & Mean (SD) & $1.0(0.2)$ & $0.9(0.2)$ & $0.9(0.2) \dagger$ & 0.003 \\
\hline
\end{tabular}

*HFmrEF with HFpEF.

†HFrEF with HFpEF.

\#HFrEF with HFmrEF.

$\mathrm{EF}$, ejection fraction; HF, heart failure; HFmrEF, HF due to midrange EF; HFpEF, HF with preserved EF; HFrEF, HF due to reduced EF ; IVSd, interventricular septum in diastole ; PWTd, posterior wall thickness in diastole. 
Table 4 Characteristics of all patients with LVEF of $40 \%$ or more in relation to cardiac dysfunction type HFmrEF, HFpEF and no dysfunction (no HF)

\begin{tabular}{|c|c|c|c|c|}
\hline \multirow[b]{3}{*}{ Characteristics } & \multirow{2}{*}{$\begin{array}{l}\text { LVEF 40-49 } \\
\text { HFmrEF }\end{array}$} & \multicolumn{2}{|l|}{ LVEF $\geq 50 \%$} & \multirow[b]{2}{*}{$P$ value } \\
\hline & & HFpEF & No HF & \\
\hline & $\mathrm{N}=34$ & $\mathrm{~N}=137$ & $\mathrm{~N}=38$ & trend \\
\hline Age, mean (SD) & $77.2(12.0)$ & $77.1(11.3)$ & $72.9(11.6)$ & 0.110 \\
\hline Male, n (\%) & $19(55.9)$ & $43(31.4)$ & $16(42.1)$ & 0.275 \\
\hline NT-proBNP ng/L, median (IQR) & $\begin{array}{l}3496 \\
(1246-6797)\end{array}$ & $\begin{array}{l}2008 \\
(1161-3356)\end{array}$ & $\begin{array}{l}996 \\
(551-3729)\end{array}$ & $<0.001$ \\
\hline \multicolumn{5}{|l|}{ Presumptive reason for dyspnoea } \\
\hline Cardiac dyspnoea & $30(88.2 \%)$ & $91(66.4 \%)$ & $28(73.7 \%)$ & 0.207 \\
\hline Non-cardiac dyspnoea & $4(11.8 \%)$ & $46(33.6 \%)$ & $10(26.3 \%)$ & \\
\hline eGFR, mean (SD) & $62.8(23.6)$ & $67.5(25.4)$ & $83.4(31.4)$ & 0.002 \\
\hline Charlson Comorbidity Index, mean (SD) & $2.3(1.8)$ & $2.5(2.1)$ & $1.6(1.3)$ & 0.106 \\
\hline Boston score, median (IQR) & $7.5(5,9)$ & $7(6,9)$ & $7.5(7,8)$ & 0.737 \\
\hline Framingham HF positive & $21(61.8 \%)$ & $65(47.4 \%)$ & $14(36.8 \%)$ & 0.036 \\
\hline \multicolumn{5}{|l|}{ Echocardiography, structural values } \\
\hline IVSd (cm), mean (SD) & $1.1(0.2)$ & $1.0(0.2)$ & $0.9(0.2)$ & $<0.001$ \\
\hline LVDd (cm), mean (SD) & $5.0(0.7)$ & $4.6(0.6)$ & $4.2(0.5)$ & $<0.001$ \\
\hline LA vol index, mean (SD) mL/m² & $58.7(20.4)$ & $51.8(15.9)$ & $27.4(4.4)$ & $<0.001$ \\
\hline LV mass index, mean (SD) & $97.4(20.6)$ & $87.8(23.0)$ & $63.6(11.5)$ & $<0.001$ \\
\hline LV hypertrophy & $8(25.0 \%)$ & $32(26.4 \%)$ & $0(0.0 \%)$ & 0.001 \\
\hline \multicolumn{5}{|l|}{ Diastolic dysfunction, four criteria } \\
\hline LA volume index $\geq 34$ mL/m² BSA & $31(91.2 \%)$ & $131(95.6 \%)$ & $0(0.0 \%)$ & $<0.001$ \\
\hline TR velocity $\geq 2.8 \mathrm{~m} / \mathrm{s}$ & $15(60 \%)$ & $65(68 \%)$ & $14(52 \%)$ & 0.512 \\
\hline$E / e^{\prime}>14$ & $18(52.9 \%)$ & $59(43.1 \%)$ & $5(13.2 \%)$ & $<0.001$ \\
\hline $\mathrm{e}^{\prime}$ reduced & $32(94.1 \%)$ & $119(86.9 \%)$ & $31(81.6 \%)$ & 0.116 \\
\hline \multicolumn{5}{|l|}{ Diastolic function, grading } \\
\hline Normal (0 or 1 criteria) & $2(5.9 \%)$ & $12(8.8 \%)$ & $23(60.5 \%)$ & $<0.001$ \\
\hline Indeterminate (exactly 2 criteria) & $11(32.4 \%)$ & $43(31.4 \%)$ & $15(39.5 \%)$ & \\
\hline Definite abnormal ( 3 or 4 criteria) & $21(61.8 \%)$ & $82(59.9 \%)$ & $0(0.0 \%)$ & \\
\hline
\end{tabular}

BSA, body surface area;EF, ejection fraction; HF, heart failure; HFmrEF, HF due to midrange EF; HFpEF, HF with preserved EF; HFrEF, HF due to reduced EF; IVSd, interventricular septum in diastole;LA, left atrium; LVDd, left ventricular diameter in diastole; TR, Tricuspid regurgitation; eGFR, estimated glomerular filtration rate; LA vol index, left atrium volume index.

to admit patients. It is also a limitation that our data are obtained in a single centre, but transferability of our results may be ensured by using the same objective selection criteria based on NT-proBNP, acute coronary syndrome and renal dysfunction.

\section{IMPLICATION}

This study reflects what would be the outcome of making a comprehensive examination in consecutive hospitalised patients with dyspnoea and elevated NT-proBNP. Current guidelines already recommend natriuretic peptide testing and/or echocardiography in hospitalised patients with suspected acute $\mathrm{HF}^{4}{ }^{4}$ However, the overwhelming problem is 'when to suspect heart failure' among the many hospitalised patients with unclear signs and symptoms. This study supports making a comprehensive echocardiogram in all patients presenting with dyspnoea and elevated NT-proBNP disregard of presumptive cause of dyspnoea although using differential NT-proBNP threshold values. Our study also indicates that a new hypothetical drug for 'essential' HFpEF may only be applicable to about 1 in 10 patients hospitalised for HF, meaning that a diagnostic and therapeutic dilemma still exists for the majority of patients who fulfil echocardiographic criteria for HFpEF. It is not known if such patients would benefit from a cardiologist advice, and there are ongoing trials to examine if prognosis of HFpEF can be improved by use of a multidisciplinary integrated care management. ${ }^{26}$

Contributors OWN and LK conceived and designed the research idea. CMC acquired, extracted and coded the data for analysis. CMC, LK and OWN met regularly to adjudicate diagnoses and interpret the data. OWN, LK and AS performed the statistical analysis. OWN drafted the manuscript. NV, AF-B and AS 
provided clinical input to the project and made critical revisions to the manuscript. All authors gave final approval of the manuscript. OWN is the overall guarantor of the manuscript.

Funding This work was funded by the Danish Heart Foundation in 2009 with a grant to CMC.

Competing interests None declared.

Patient consent for publication Obtained.

Provenance and peer review Not commissioned; externally peer reviewed.

Data availability statement Data may be obtained from a third party and are not publicly available.

Open access This is an open access article distributed in accordance with the Creative Commons Attribution Non Commercial (CC BY-NC 4.0) license, which permits others to distribute, remix, adapt, build upon this work non-commercially, and license their derivative works on different terms, provided the original work is properly cited, appropriate credit is given, any changes made indicated, and the use is non-commercial. See: http://creativecommons.org/licenses/by-nc/4.0/.

\section{REFERENCES}

1. Kelly JP, Mentz RJ, Mebazaa A, et al. Patient selection in heart failure with preserved ejection fraction clinical trials. J Am Coll Cardiol 2015;65:1668-82.

2. Ferrari R, Böhm M, Cleland JGF, et al. Heart failure with preserved ejection fraction: uncertainties and dilemmas. Eur $\mathrm{J}$ Heart Fail 2015;17:665-71.

3. Triposkiadis F, Giamouzis G, Parissis J, et al. Reframing the association and significance of co-morbidities in heart failure. Eur $J$ Heart Fail 2016;18:744-58.

4. Ponikowski P, Voors AA, Anker SD, et al. 2016 ESC guidelines for the diagnosis and treatment of acute and chronic heart failure. Eur Heart J 2016;37:2129-200.

5. Nagueh SF, Smiseth OA, Appleton CP, et al. Recommendations for the evaluation of left ventricular diastolic function by echocardiography: an update from the American Society of echocardiography and the European association of cardiovascular imaging. Eur Heart J Cardiovasc Imaging 2016;17:1321-60.

6. CM C. Patients Admitted with Heart Failure: Implications of Natriuretic Peptides and Preserved Ejection Fraction : PhD Thesis. University of Copenhagen, 2014

7. Januzzi JL, van Kimmenade R, Lainchbury J, et al. NT-proBNP testing for diagnosis and short-term prognosis in acute destabilized heart failure: an international pooled analysis of 1256 patients: the international collaborative of NT-proBNP study. Eur Heart $J$ 2006;27:330-7.

8. Hill SA, Booth RA, Santaguida PL, et al. Use of BNP and NT-proBNP for the diagnosis of heart failure in the emergency department: a systematic review of the evidence. Heart Fail Rev 2014;19:421-38.

9. Lang RM, Bierig M, Devereux RB, et al. Recommendations for chamber quantification. Eur J Echocardiogr 2006;7:79-108.
10. Nagueh SF, Appleton CP, Gillebert TC, et al. Recommendations for the evaluation of left ventricular diastolic function by echocardiography. Eur J Echocardiogr 2009;10:165-93.

11. Paulus WJ, Tschöpe $C$, Sanderson JE, et al. How to diagnose diastolic heart failure: a consensus statement on the diagnosis of heart failure with normal left ventricular ejection fraction by the heart failure and echocardiography associations of the European Society of cardiology. Eur Heart J 2007;28:2539-50.

12. Jiamsripong $P$, Honda $T$, Reuss CS, et al. Three methods for evaluation of left atrial volume. Eur J Echocardiogr 2008;9:351-5.

13. Ho KK, Pinsky JL, Kannel WB, et al. The epidemiology of heart failure: the Framingham study. J Am Coll Cardiol 1993;22(4 Suppl A):6A-13

14. Marantz PR, Tobin JN, Wassertheil-Smoller S, et al. The relationship between left ventricular systolic function and congestive heart failure diagnosed by clinical criteria. Circulation 1988;77:607-12.

15. Charlson ME, Pompei $P$, Ales KL, et al. A new method of classifying prognostic comorbidity in longitudinal studies: development and validation. J Chronic Dis 1987;40:373-83.

16. Frenkel WJ, Jongerius EJ, Mandjes-van Uitert MJ, et al. Validation of the Charlson comorbidity index in acutely hospitalized elderly adults: a prospective cohort study. J Am Geriatr Soc 2014;62:342-6.

17. Shah AM, Claggett B, Kitzman D, et al. Contemporary assessment of left ventricular diastolic function in older adults: the Atherosclerosis Risk in Communities study. Circulation 2017;135:426-39.

18. Paulus WJ, Tschöpe C. A novel paradigm for heart failure with preserved ejection fraction: comorbidities drive myocardial dysfunction and remodeling through coronary microvascular endothelial inflammation. J Am Coll Cardiol 2013;62:263-71.

19. Lam CSP, Solomon SD. The middle child in heart failure: heart failure with mid-range ejection fraction (40-50\%). Eur J Heart Fail 2014;16:1049-55.

20. Teerlink JR, Voors AA, Ponikowski P, et al. Serelaxin in addition to standard therapy in acute heart failure: rationale and design of the RELAX-AHF-2 study. Eur J Heart Fail 2017;19:800-9.

21. Packer M, O'Connor C, McMurray JJV, et al. Effect of Ularitide on cardiovascular mortality in acute heart failure. $N$ Engl J Med 2017;376:1956-64.

22. Ibrahim I, Kuan WS, Frampton $C$, et al. Superior performance of $\mathrm{N}$-terminal pro brain natriuretic peptide for diagnosis of acute decompensated heart failure in an Asian compared with a Western setting. Eur J Heart Fail 2017;19:209-17.

23. Barr RG, Bluemke DA, Ahmed FS, et al. Percent emphysema airflow obstruction, and impaired left ventricular filling. $N$ Engl $\mathrm{J}$ Med 2010;362:217-27.

24. Mentz RJ, Maddox TM. Targeting comorbidities in elderly patients with heart failure: the OPTIMIZE-HFPEF trial. J Card Fail 2016;22:545-7

25. Butler J, Chirovsky D, Phatak $\mathrm{H}$, et al. Renal function, health outcomes, and resource utilization in acute heart failure: a systematic review. Circ Heart Fail 2010;3:726-45.

26. Fu M, Zhou J, Thunström E, et al. Optimizing the management of heart failure with preserved ejection fraction in the elderly by targeting comorbidities (OPTIMIZE-HFPEF). J Card Fail 2016;22:539-44 